\title{
INDICADORES DE SUSTENTABILIDADE URBANA NA BACIA DO RIO BELÉM, VILA HAUER, CURITIBA - PR
}

\section{INDICATORS OF URBAN SUSTAINABILITY IN VILA HAUER, CURITIBA - PR}

\section{Gislene Melo}

Universidade Federal do Paraná, Curitiba-PR, discente de mestrado. E-mail:

teacher.gislene.melo@gmail.com

Gustavo Yuri Mine Misael Universidade Federal do Paraná, Curitiba-PR, discente de mestrado e professor da Faculdades Integradas

Camões, curso de Gestão

Ambiental. E-mail:

gustavoyuri_misael@yahoo.com.br

Natália Siqueira

Universidade Federal do Paraná, Curitiba-PR, discente de mestrado E-mail: nattalia.persi@gmail.com

\section{RESUMO}

Este trabalho tem como objetivo avaliar indicadores de sustentabilidade baseando-se em princípios do urbanismo ecológico de Rueda (2006) em uma área da Vila Hauer, na cidade de Curitiba - PR. Elencaram-se aspectos como cobertura vegetal, usos do solo e mobilidade para realizar análises quali-quantitativas, tais como índice de cobertura vegetal baseado em Harder (2006) e Misael (2015), além de usos do solo e mobilidade com relação aos espaços para pedestres e vias, baseados no método de quantificação de Campos et al. (2005). As informações obtidas são resultado de levantamentos em campo juntamente com dados adquiridos em fontes oficiais. Apenas a cobertura vegetal apresenta índice satisfatório quanto à sustentabilidade urbana. Concluiu-se que a área ainda precisa de melhor intervenção com projetos que melhorem a qualidade ambiental local, visto que somente está melhor servida de cobertura vegetal, estando os outros indicadores com baixo desempenho com relação à indicadores e índices de sustentabilidade. A análise permitiu compreender como características físicas e socioeconômicas influenciam diretamente na sustentabilidade urbana.

Palavras-chave: Sustentabilidade. Indicadores. Vila Hauer. Urbanismo ecológico.

\begin{abstract}
This work had as objective evaluates sustainability indicators basing on beginnings of ecological urbanization of Rueda (2006) in na área of the Vila Hauer, in the Curitiba City-PR.It was chosen aspects as vegetable covering, uses of the soil and mobility to accomplish quali-quantitative analyses, such as index of vegetable covering based on Harder (2006) and Misael (2015); uses of the soil and mobility regarding the spaces of pedestrian and roads, based on the method of quantification of Campos et al (2005). The obtained informations are resulted together of risings in field with acquired data in official sources. Only the vegetation cover presents satisfactory index as to urban sustainability. It was end that the area still needs of better intervention with projects than they improve the local environmental quality, because it is only better served of covering vegetable, being the other indicators with low acting regarding to indicators and sustainability indexes. The analysis allowed to understand physical and socioeconomic characteristics influence directly in the urban sustainability.
\end{abstract}

Keywords: Sustainability. Indicators. Vila Hauer. Ecological urbanization. 


\section{INTRODUÇÃO}

O acelerado processo de urbanização atual encadeou uma série de problemas referentes à relação meio ambiente e espaço urbano, em que os recursos naturais não são aproveitados da melhor forma e acabam por se esgotar sem que se possa utilizá-los como fonte essencial para a vida humana. O que se observa é a constante mudança na paisagem natural em consequência da produção capitalista exacerbada com enfoque no excedente e deixando a questão ambiental em segundo plano.

De acordo com Mendonça (1994), a falta de planejamento na orientação do desenvolvimento das cidades brasileiras gerou ambientes urbanos com elevados níveis de degradação, não somente porque o planejamento urbano não consegue alcançar o rápido processo de urbanização, mas também porque se observa um desinteresse político para a criação e implementação de mecanismos de combate ao declínio da qualidade de vida no ambiente urbano.

Para que as cidades não entrem em um colapso quanto aos recursos naturais, ou caos ambiental, social e econômico, faz-se necessário pensar e adotar práticas de sustentabilidade urbana, minimizando impactos que podem refletir diretamente na qualidade de vida da população.

De acordo com Sachs (2002), a sustentabilidade deve ser ecológica, mas também social, econômica, espacial e cultural. Todo o planejamento de desenvolvimento precisa levar em conta, simultaneamente, essas cinco dimensões: ecológica, social, econômica, espacial e cultural.

Muitos autores têm trabalhado o planejamento das cidades visando aliar planejamento e sustentabilidade. Conforme Edwards (2008, p.15), "o conceito de sustentabilidade envolve a noção do meio ambiente como um sistema holístico e interdisciplinar”. Segundo Acselrad (2001), a sustentabilidade não se refere apenas ao meio ambiente, mas também às questões econômicas, sociais e políticas, e essas devem estar entrelaçadas em todas as suas esferas para embasar uma discussão.

Dentro dessa vertente da sustentabilidade, o urbanismo ecológico surge com algumas teorias, práticas e métodos de se trabalhar a sustentabilidade urbana. Rueda (2006) e Spirn (2011) trazem ideias de urbanismos ecológico que incluem áreas verdes e cobertura vegetal, usos do solo, tipos de habitação, conectividade e mobilidade urbana e acessibilidade como práticas dentro do planejamento e da gestão do espaço urbano. 
De acordo com o conceito de urbanismo ecológico de Rueda (2006), as condições ecológicas do lugar estão sendo pouco aproveitadas, o solo é pouco utilizado para produção de alimentos ou para compostagem e o lixo é recolhido para coleta, porém muito ainda vai para o meio ambiente. O rio não é aproveitado para abastecer de água as casas próximas, não é usado para transporte ou lazer, nem para sustentabilidade energética, como o resfriamento de telhados.

O urbanismo ecológico, portanto, está ligado à sustentabilidade das cidades, à eficiência e à qualidade de seus serviços e de sua infraestrutura, defendendo abordagens mais holísticas na produção e na gestão dos espaços urbanos. Para Spirn (2011), a filosofia que embasa o ideal do urbanismo ecológico já está presente em nossas sociedades há tempos, uma vez que, desde os gregos antigos, já existiam análises capazes de descrever os efeitos do ar, das águas e dos lugares na saúde dos indivíduos e das comunidades.

O conceito de cidades compactas e difusas também influencia na sustentabilidade urbana. Para Rueda (2006), a análise dicotômica entre os dois modelos opostos de ocupação urbana - a cidade compacta e a difusa - permite estabelecer critérios de análise que comparam a eficácia dos sistemas. A minimização do consumo de materiais, energia e água, bem como a otimização de infraestrutura, o aumento da complexidade dos sistemas e a coesão social destacam a supremacia do modelo compacto sobre o difuso, na promoção da sustentabilidade urbana.

Conforme Edwards (2008), para um desenvolvimento sustentável urbano, os princípios são a compactação, ruas livres de tráfego intenso, maior densidade nas áreas suburbanas, mais uso misto do solo, edificações residenciais de quatro pavimentos e legibilidade. $\mathrm{O}$ autor afirma que o único modelo de cidade sustentável possível é a cidade compacta e de uso misto.

Aliado a isso, os indicadores e atributos têm sido empregados para se caracterizar a sustentabilidade urbana. O uso de indicadores de sustentabilidade urbana tem sido explorado nos últimos anos em muitas pesquisas e até mesmo como base para o planejamento urbano de algumas cidades no mundo. Indicadores como compactação, usos mistos, áreas verdes e cobertura vegetal, tipos de habitação, mobilidade e conectividade, resíduos, água, solo e ar são os principais indicadores utilizados para se caracterizar a sustentabilidade urbana, conforme descrevem Rueda (2006) e Nunes et al. (2016).

"Indicadores construídos ou de confiabilidade devem ter relevância, responder a um objetivo específico, validade, desagregabilidade de indicadores em grupos, periodicidade, 
historicidade, ou seja, passível de comparação com um tempo no passado" (PEREIRA et al., 2015, p. 330).

Na cidade de Curitiba, conhecida internacionalmente por seu planejamento urbano e por seus programas ambientais, existe uma grande diversidade de bairros, apresentando variadas tipologias de usos e ocupação do solo e, consequentemente, com diferentes aspectos socioambientais.

Porém, com o rápido crescimento das últimas décadas, aliado ao aumento do interesse imobiliário, muitos problemas urbanos passaram também a surgir, como a poluição de rios e do ar, ocupação irregular ao longo dos rios, disposição inadequada de resíduos e diminuição da cobertura vegetal.

\section{OBJETIVOS}

O objetivo deste trabalho foi avaliar indicadores de sustentabilidade urbana e de urbanismo ecológico (cobertura vegetal, usos mistos do solo e mobilidade) de uma configuração urbana de média densidade, no entorno do rio Belém, em uma área na Vila Hauer, no município de Curitiba, com a finalidade de entender quais fatores influenciam no nível de sustentabilidade de um local.

A justificativa para a escolha da área se deu por se tratar de uma área com usos mistos do solo, assim como toda a região dos bairros Vila Hauer e Boqueirão, remetendo à ideia de cidade compacta, por possuir vários tipos de usos, que atendem à população.

Outra justificativa é de que poucos estudos se têm encontrado com relação a essa temática na bacia do rio Belém, e por se tratar de uma bacia altamente urbanizada (pois corta a área urbana de Curitiba no eixo Norte-Sul), pretendendo, assim, produzir conhecimento através de obtenção de dados, vivência e análise em campo, desenvolvendo uma pesquisa quali-quantitativa.

Com esta pesquisa, espera-se que desperte na sociedade civil maior atenção com relação a essa temática, servindo de subsídios a um planejamento urbano e ambiental adequado e igualitário, proporcionando soluções e intervenções urbanísticas, visando à melhoria da qualidade ambiental local e, consequentemente, a qualidade de vida da população.

\section{MÉTODO}

ÁREA DE ESTUDO 
Segundo Fendrich,

a Bacia Hidrográfica do Rio Belém está localizada geograficamente desde as nascentes $($ Cota Topográfica $=990,00 \mathrm{~m})$ até a foz $($ Cota Topográfica $=870 \mathrm{~m})$, dentro dos limites geográficos do município de Curitiba, sendo tributário da margem direita do Rio Iguaçu. Seu talvegue principal desenvolve-se segundo a orientação Norte-Sul, cortando regiões de alto grau de densidade populacional como bairros periféricos das Zonas Norte e Sul e a Zona Central da cidade de Curitiba (2002, p. 5).

De acordo com Bollmann,

a Bacia do Rio Belém possui $84 \mathrm{~km}^{2}$, sua área de drenagem representa cerca de $20 \%$ da área do Município de Curitiba e abriga aproximadamente $50 \%$ de sua população. Engloba os principais bairros da cidade, entre eles o Centro e os principais pontos notáveis naturais e arquitetônicos que tem representado a Cidade de Curitiba, conferindo-lhe uma grande importância simbólica, consideradas as dimensões geográfica, social, econômica e cultural. Por isso, a bacia do rio Belém é considerada de extrema importância para a cidade de Curitiba (2008, p. 443).

A bacia do rio Belém é uma das principais bacias hidrográficas de Curitiba e, por estar totalmente em área urbana, possui sérios problemas ambientais, como supressão da vegetação, ocupações irregulares, canalização de seu leito, lançamentos de alta carga de esgoto sanitários e industriais, acúmulo de resíduos e enchentes.

Possui também grande complexidade urbana, quanto aos usos do solo. Ao norte da Bacia, encontram-se áreas tipicamente residenciais mescladas com alguns comércios e, na parte sul da bacia, áreas de usos mistos do solo, mesclando residências, comércios e indústrias.

A área selecionada localiza-se na Vila Hauer, no sul da bacia do rio Belém, ao sul do centro da cidade de Curitiba, na regional Boqueirão (Figura 1).

Segundo dados do IPPUC (2010), a Vila Hauer possui uma população de 13315 habitantes, uma área de $3990000 \mathrm{~m}^{2}$ e uma densidade demográfica de $3337 \mathrm{hab} / \mathrm{km}^{2}$. Possui em sua maior parte domicílios do tipo casas $(75,1 \%)$ e boa infraestrutura de água, esgoto e coleta de lixo (próximos de $100 \%$ de atendimento). Em relação às atividades econômicas predominantes no bairro, a maior parte está ligada ao comércio e serviços $(86,84 \%)$, seguida pelas indústrias (12,07\%). Possui renda média entre os domicílios de R $\$ 3486,52$. Possui 33,33 de $\mathrm{m}^{2} /$ hab de áreas de verdes, contando com cinco praças de lazer (IPPUC, 2010). 
Figura 1 - Localização da área de estudo, Vila Hauer, Curitiba - PR

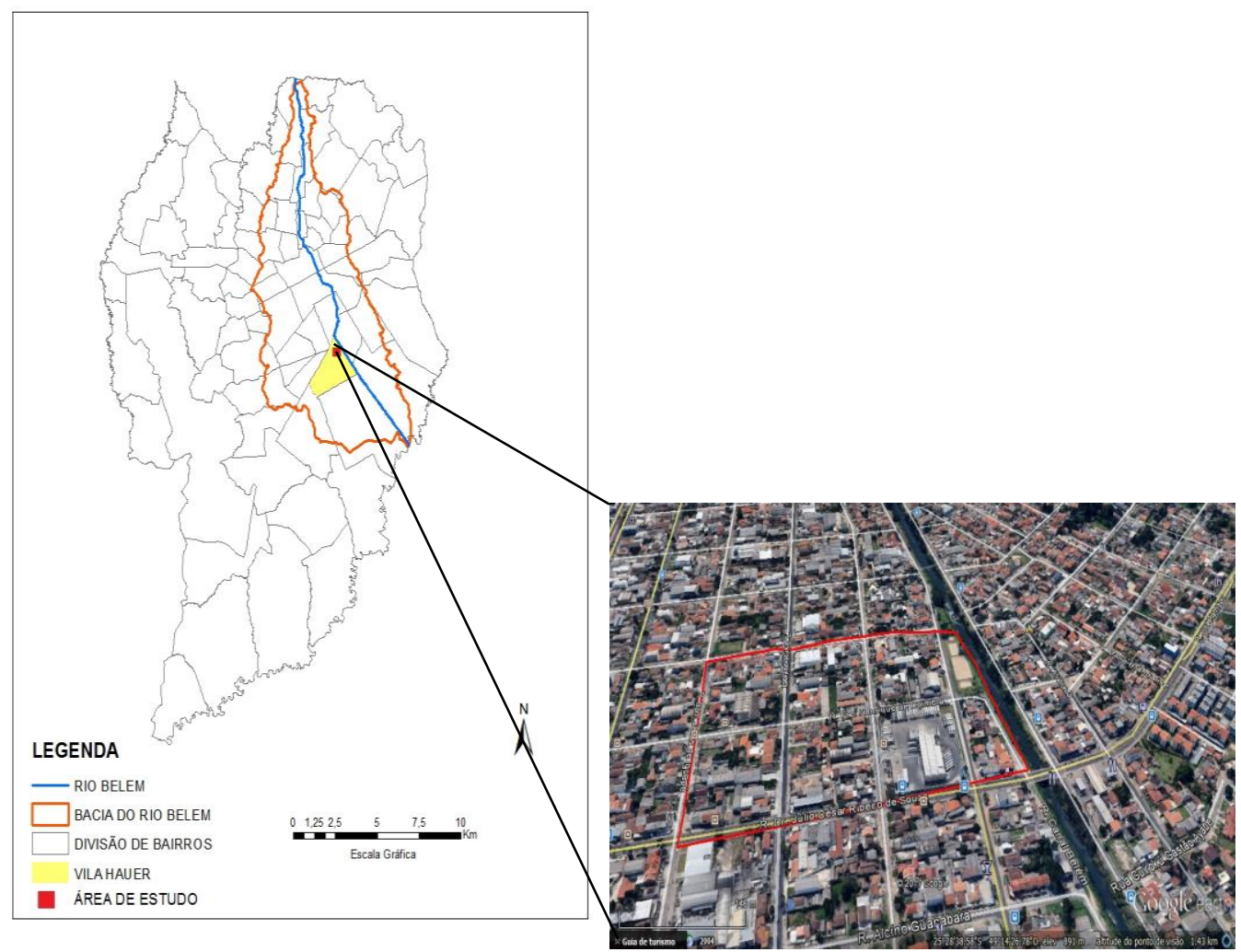

Fonte: Adaptado de (Instituto de Terras, Cartografia e Geociências do Paraná; 2017; ArGis 10.2; Google Earth Pro, $2017^{2}$ ).

A área de estudo está delimitada ao norte pela rua São Bento, ao sul pela rua Dr. Júlio Ribeiro de Souza, ao oeste pela rua Bom Jesus de Iguape e ao leste pela rua Canal Belém às margens do rio Belém, totalizando uma área de $12000 \mathrm{~m}^{2}$, nas proximidades do rio Belém (conforme Figura 1), no trecho conhecido por Canal Belém, que, no entanto, encontra-se aberto. Possui uma população estimada de cerca de 400 habitantes. Caracteriza-se por ser uma área com usos mistos do solo, próximo ao rio Belém (margem esquerda), o qual se encontra em estado de alto grau de poluição, por esgotos domésticos e industriais (Figura 2).

Figura 2 - Rio Belém em estado degradado por poluição, próximo da área de estudo, na Vila Hauer 


\section{PROCEDIMENTOS}

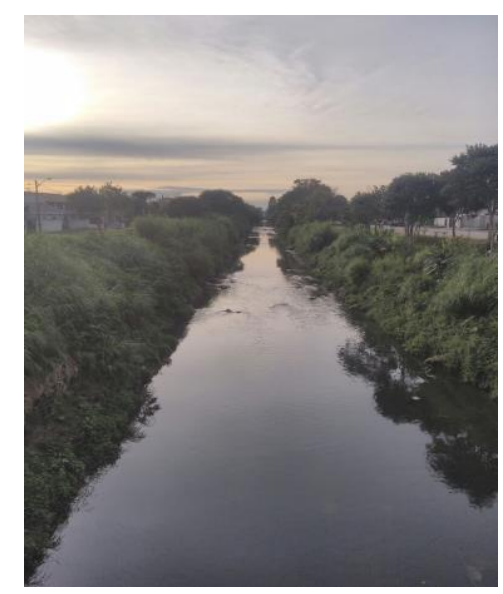

Fonte: Acervo dos autores, 2017.

Para analisar os indicadores de sustentabilidade urbana, foram utilizadas as teorias sobre urbanismo ecológico de Rueda (2006), que abrangem aspectos como complexidade urbana (usos mistos do solo), biodiversidade urbana (áreas verdes e vegetação), habitação e cidades compactas.

São sete os indicadores de urbanismo ecológico apontados por Rueda (2006):

1. Áreas verdes.

2. Mobilidade.

3. Ocupação do solo.

4. Habitabilidade do espaço público.

5. Complexidade urbana.

6. Coesão social.

7. Massa crítica.

O foco das análises foi em áreas verdes e cobertura vegetal, complexidade urbana (ocupação e usos do solo) e mobilidade urbana (espaços para pedestres e vias disponíveis e transporte público). Realizaram-se visitas em área, a fim de averiguar os aspectos elencados.

Para a análise da cobertura vegetal, bem como para determinar o índice de cobertura vegetal por habitante, adotou-se o método utilizado por Misael (2015) na quantificação da cobertura vegetal nas APPs do rio Belém e o procedimento adotado por Harder et al. (2006) para o município de Vinhedo - SP, obtido pelo seguinte cálculo:

$\mathrm{ICV}=\sum$ (áreas de vegetação) $/ \mathrm{n}^{\mathrm{o}}$ habitantes.

Com a utilização do software Google Earth Pro, com imagens do ano de 2017, criaramse polígonos sobre a cobertura vegetal, e, com a soma de todas as áreas esses polígonos, obteve-se a área total em cobertura vegetal no recorte espacial. Como a população estimada 
no recorte, com base na densidade demográfica do IPPUC (2010), foi de 399 habitantes, pôde-se chegar ao índice de cobertura vegetal por habitante, obtido através do cálculo:

$\mathrm{ICVh}=\sum$ (Área total de cobertura vegetal) / número de habitantes.

Para a análise dos usos do solo, utilizou-se o software Google Earth Pro, com imagens do ano de 2017, através do qual foi possível quantificar os usos do solo na área do recorte espacial, com a criação de polígonos e com a soma de suas áreas e cálculos em relação à área total do recorte.

Para análise dos espaços para pedestres e vias públicas, foi realizado um levantamento de campo em que foram observados problemas com relação aos espaços para pedestres, baseando-se em Campos e Ramos (2005), que descreve como medir indicadores de mobilidade sustentável. Assim, para quantificar a relação de espaços para pedestres (calçadas e caminhos) e vias públicas (ruas), utilizou-se imagens do software Google Earth Pro, e através destas, criou-se polígonos sobre as ruas, calçadas e, com a soma de suas áreas, obteve-se a relação de proporção entre calçadas e ruas em km.

Para a análise com relação ao atendimento de linhas de ônibus na área, utilizou-se dados obtidos disponibilizados através do IPPUC (Instituto de Pesquisa e Planejamento Urbano de Curitiba) e análises em campo.

\section{RESULTADOS E DISCUSSÕES}

\section{COBERTURA VEGETAL}

Obteve-se a área total em cobertura vegetal no recorte espacial, que foi de $16683,2 \mathrm{~m}^{2}$, representando um percentual de $13,92 \%$ da área do recorte espacial. O valor de cobertura vegetal encontrado foi de $42 \mathrm{~m}^{2} / \mathrm{hab}$ ou $0,0042 \mathrm{ha} / \mathrm{hab}$. Aqui, levaram-se em conta como cobertura vegetal as árvores, os arbustos, vegetação herbácea e rasteira (Figura 3).

Figura 3 - Croqui com cobertura vegetal em destaque 


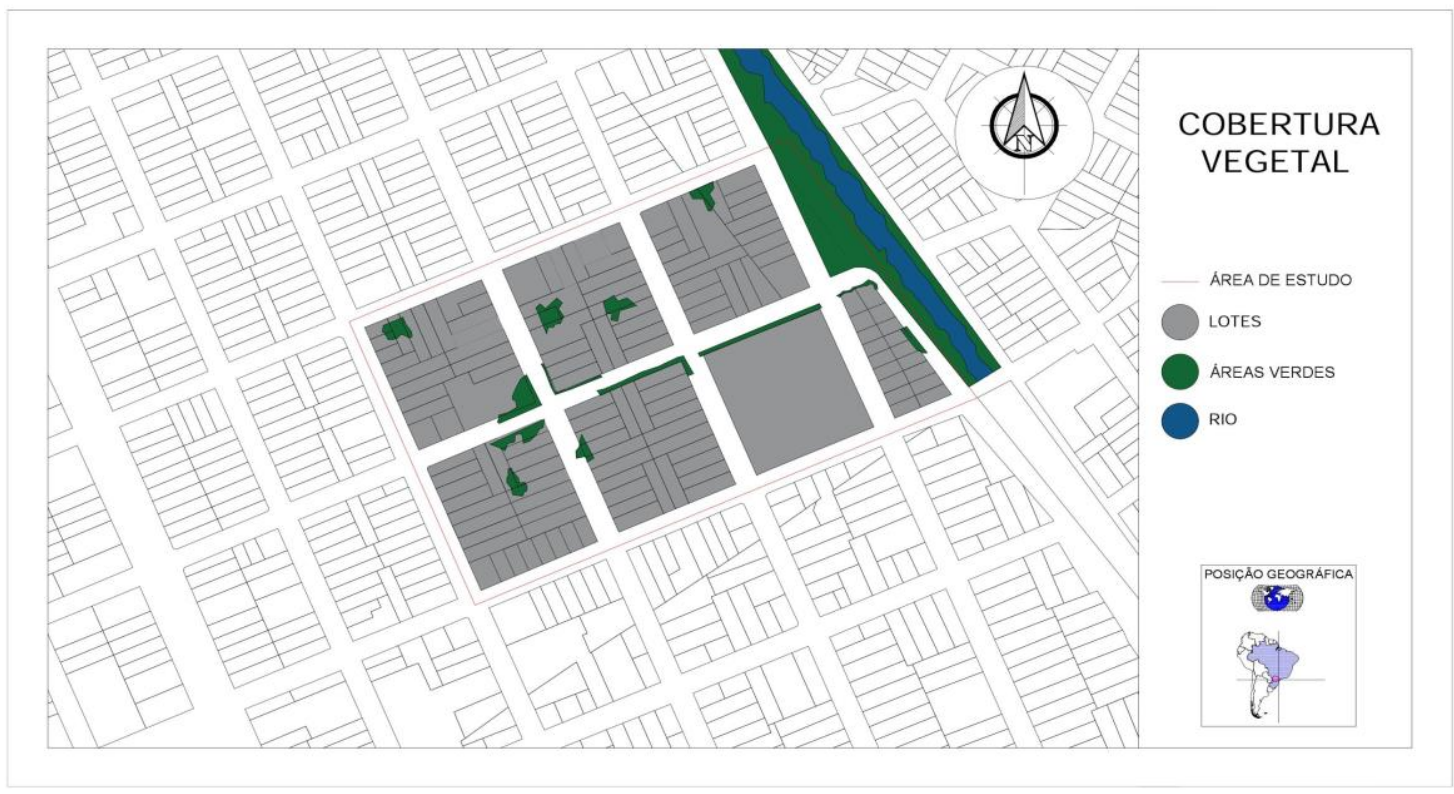

Fonte: Adaptado de base de dados do IPPUC, 2017'; AutoCad, $2017^{2}$.

Considera-se esse número ainda abaixo do estimado pela PMC (Prefeitura Municipal de Curitiba) para a média de cobertura vegetal do município por habitante, que é, segundo dados do IPPUC, $58 \mathrm{~m}^{2} / \mathrm{hab}$. Em relação à média do bairro Vila Hauer, que compreende $33,3 \mathrm{~m}^{2} / \mathrm{hab}$ (IPPUC, 2014), classifica-se como mediana, mas, se comparada com os dados da cidade, ainda se situa abaixo. Já a OMS (Organização Mundial da Saúde) recomenda $12 \mathrm{~m}^{2} / \mathrm{hab}$ de área verde/cobertura vegetal, e a Sociedade Brasileira de Arborização Urbana (SBAU) $15 \mathrm{~m}^{2} / \mathrm{hab}$, estando a área, portanto, acima do recomendado.

Segundo Jesus e Braga (2005), o índice de áreas verdes expressa a relação entre a área dos espaços verdes de uso público, em $\mathrm{km}^{2}$ ou $\mathrm{m}^{2}$, e a quantidade de habitantes de uma determinada cidade. Nesse cálculo, estão incluídas as praças, os parques e similares, ou seja, aqueles espaços cujo acesso da população é livre.

Observou-se que, nas quadras percorridas no decorrer do trajeto, os espaços verdes existentes foram produtos de intervenção popular que, na ausência de iniciativa pública, optou por plantar espécies arbóreas que não se classificam como arborização viária ideal (Figura 4), pois:
a) não possuem o porte adequado;
b) muitas não são espécies endêmicas; 
c) não seguem padronização no desenho urbano. No entanto, indicam uma apropriação popular do espaço urbano, sendo que muitos quintais apresentam ,inclusive, espécies frutíferas, por exemplo, limão, mimosas.

O plantio de árvores e arbustos sem um prévio planejamento e escolha de espécies adequadas e nativas da região pode ocasionar desequilíbrios ecológicos entre espécies de flora e fauna urbana. Além disso, o uso popular de espécies usadas para paisagismo e algumas espécies frutíferas pode ser responsável por alguns desequilíbrios, como introdução de espécies exóticas ou desaparecimento e inibição de espécies nativas, tanto da flora quanto da fauna local.

Figura 4 - Ausência de arborização viária pública e presença de espécies plantadas por moradores locais

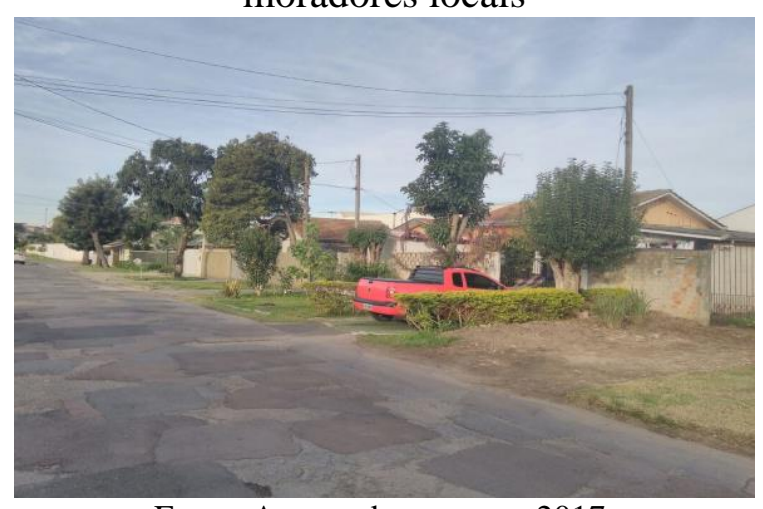

Fonte: Acervo dos autores, 2017.

De acordo com Luchiari (2001), um dos elementos diferenciadores das áreas residenciais é a porção do espaço destinado à cobertura vegetal. Essa vegetação pode estar em áreas públicas ou privadas e constituir um indicador de qualidade ambiental desses espaços.

Ocupando uma área aproximada de meia quadra nas margens do rio Belém onde deveria ser a APP (área de preservação permanente) do rio, encontra-se uma praça denominada Praça Nair Pereira Queirolo (Figura 5), que inclui um parque de crianças e idosos e um campo de futebol. Desse lado da margem, observou-se a presença de vegetação rasteira e média e superficiais arborizações que proporcionam sombra para os usuários do parque.

Figura 5 - Praça Nair Pereira Queirolo 


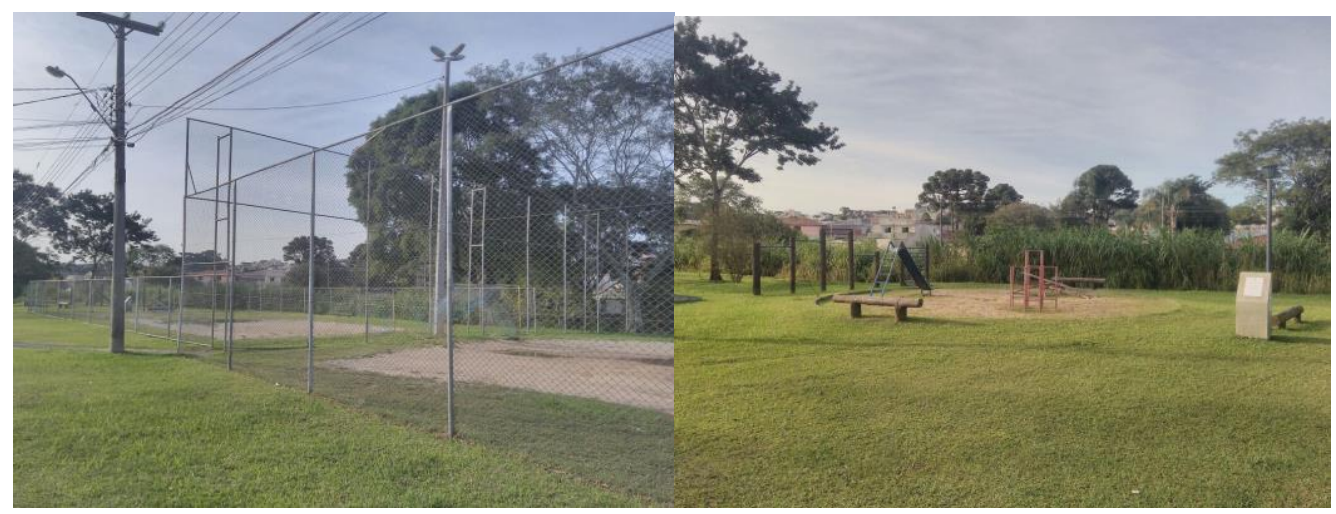

Fonte: Acervo dos autores, 2017.

Nucci e Cavalheiro (1999) definem cobertura vegetal como qualquer área provida de vegetação dentro do espaço urbano, compreendendo a vegetação arbórea, arbustiva e arbórea. Os jardins, os quintais, as praças, os canteiros em vias de circulação, as áreas preservadas, dentre outras formas de cobertura vegetal, estão compreendidas dentro dessa categoria. Essas áreas podem estar situadas tanto em terrenos públicos quanto em terrenos privados.

Conclui-se que, quanto ao aspecto áreas verdes e cobertura vegetal, a área é bem servida, estando acima da média do bairro Vila Hauer, e dos índices recomendados pela OMS e pela SBAU, considerando ainda esse aspecto o principal da relação com a natureza no meio urbano.

Alguns estudos realizados em outros municípios mostram que nem sempre esse aspecto está dentro dos parâmetros de sustentabilidade urbana. Nunes et al. (2016), ao analisarem dois bairros no município de Caxias do Sul-RS, chegaram à conclusão de que os bairros analisados de alta densidade demográfica e usos mistos do solo ainda possuem pouca cobertura vegetal em relação à área total, se comparado com o índice recomendado pela OMS.

\section{USOS DO SOLO}

A área de estudo apresenta como característica de ocupação usos mistos ou, conforme Rueda (2006), "poli funcionais"”: residencial, comercial, pequenas empresas, lazer, indústrias e estacionamentos.

Encontram-se na área categorias de usos como: habitação, institucional, misto, comércio de alimentação, lotes sem usos, serviços, imóveis para aluguel, e de lazer (Figura 6). Porém, o predomínio ainda é o de uso residencial, mas mesclado com outros, como comércios e serviços (Tabela 1$)$.

Figura 6 - Croqui com os tipos de usos do solo na área de estudo 


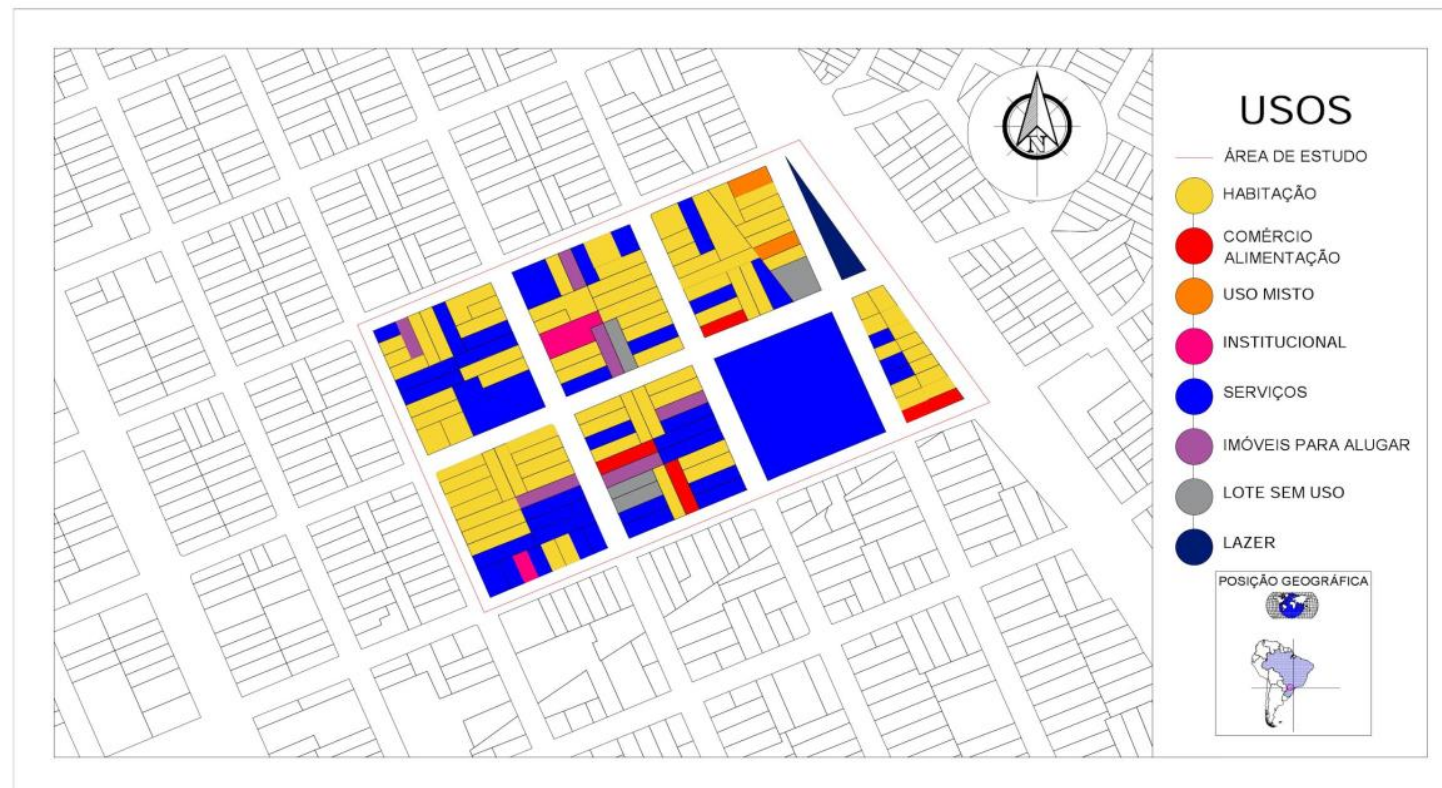

Fonte: Elaborado pelo autor, 2017.

Tabela 1 - Quantificação de classes de usos do solo na área de estudo

\begin{tabular}{ccc}
\hline Tipo de uso & Área $\left(\mathbf{m}^{2}\right)$ & \% em relação à área total \\
\hline Comercial & 29.037 & 24,17 \\
Comunitário & 5009 & 4,17 \\
Residencial & 73800 & 61,5 \\
Industrial & 1669 & 1,39 \\
\hline
\end{tabular}

Fonte: Elaborada pelos autores, 2017.

As áreas residenciais ocupam a maior porção do espaço urbano e guardam diferenciações entre elas. Essas áreas diferenciam-se por estarem próximas ou por permitirem fácil acesso aos serviços essenciais básicos, como sistema de água e esgoto, sistema de transporte, serviços educacionais, bem como ao lazer e às áreas verdes (CAMPOS FILHO, 1992). As áreas residenciais são, então, qualificadas e valorizadas pelos conjuntos moldados com diferentes graus de presença desses elementos.

Porém, perceberam-se na área muitos imóveis vazios ou à venda, assim como estabelecimentos de comércios, o que pode indicar uma desvalorização do local por parte de alguns ex-moradores ou até mesmo por moradores ainda presentes. 
Observou-se ainda que a maioria das residências é de um ou no máximo dois pavimentos (Figura 7). Porém, o padrão construtivo é bastante diversificado, tendo residências tanto de pequeno porte quanto de grande porte.

Figura 7 - Residências de um ou dois pavimentos na maior parte da área de estudo

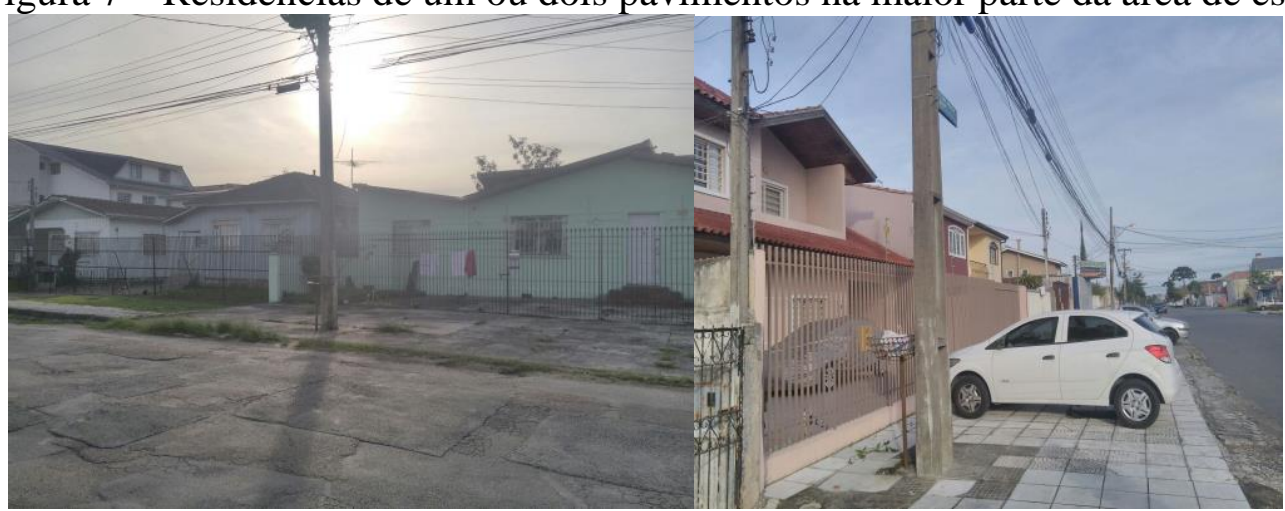

Fonte: Acervo dos autores, 2017.

Com exceção da rua de frente para o rio, a maior parte das construções segue o padrão de metragem por terreno, recuo de calçada, recuo de terreno, recuo de prédio, recuo de fundos de quintal de acordo com os padrões urbanísticos da prefeitura. Também se observou a existência de alguns galpões abandonados. Esses galpões já foram de uso industrial e da área de prestação de serviços. Estima-se que alguns foram abandonados há mais de uma década e ainda não foram dados novos usos. Os galpões também seguem uma altura predial padrão, embora abandonados (Figura 8).

Figura 08 - Presença de galpões comerciais sem uso na área

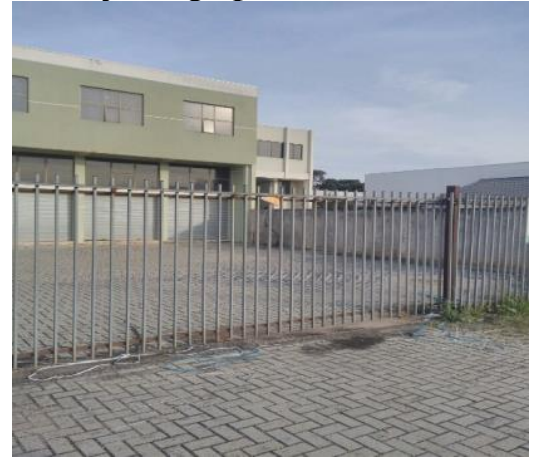

Fonte: Acervo dos autores, 2017.

Há presença de duas pequenas indústrias na área, uma de materiais de construção como calhas (Figura 9) e outra de objetos para usos em publicidade.

Figura 09 - Pequenas indústrias na área 


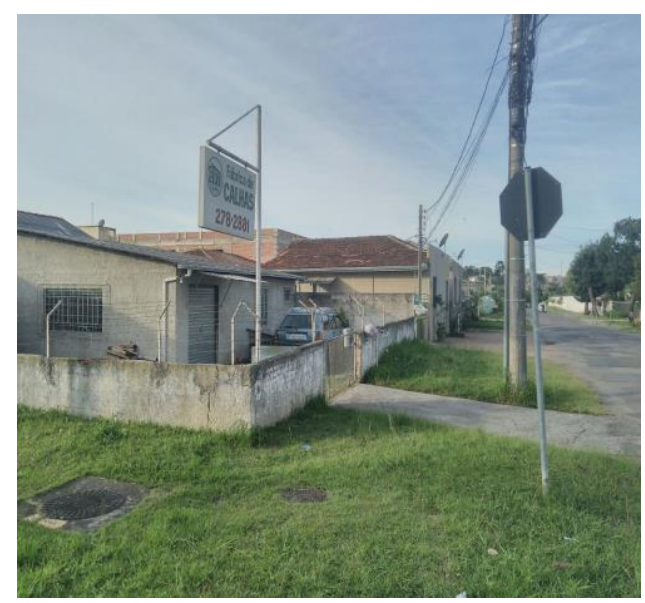

Fonte: Acervo dos autores, 2017.

Nunes et al. (2016), ao analisarem os usos mistos do solo em dois bairros de Caxias do Sul - RS, chegaram à conclusão de que a alta densidade e a heterogeneidade os usos comerciais, residenciais e industriais atendem aos critérios de cidade compacta, sendo uma área bem provida de serviços, destacando-se, principalmente, a conectividade com a natureza, por possuir áreas verdes e cobertura vegetal em meio às concentrações de usos do solo nos bairros analisados.

Conclui-se que a área, mesmo possuindo usos mistos de solo, ainda apresenta pouca heterogeneidade, cabendo destacar que alguns locais se apresentam em estado de abandono e há poucos comércios que atendem à população da área.

Os estabelecimentos comerciais e industriais, em sua maioria, não são de atendimento exclusivo da população da área, mas sim de redes e prestadoras de serviços, empresas, escolas, além da presença de serviços locais de alimentação, ofertados nas próprias residências.

Porém, a conectividade com áreas verdes e cobertura vegetal ainda é um aspecto que se destaca, em meio a essa área, conforme os índices obtidos. Mas ainda carece de um planejamento urbanístico com melhor distribuição, por exemplo, dessa cobertura e da arborização viária.

\section{MOBILIDADE: ESPAÇO PARA PEDESTRES, VIAS E ATENDIMENTO POR TRANSPORTE COLETIVO}

Em levantamento de campo, foram observados problemas relacionados aos espaços para pedestres. Com relação às calçadas disponíveis na área, essas constituem 2390m de extensão enquanto que foram levantadas $2520 \mathrm{~m}$ de vias asfaltadas. 
Observou-se também a descontinuidade das calçadas, além da presença de obstáculos como automóveis estacionados e cestos de lixo e presença de vegetação herbácea, dificultando ainda mais a mobilidade (Figura 10).

Figura 10 - Descontinuidade das calçadas e obstáculos na mobilidade. Uma característica comum na área de estudo

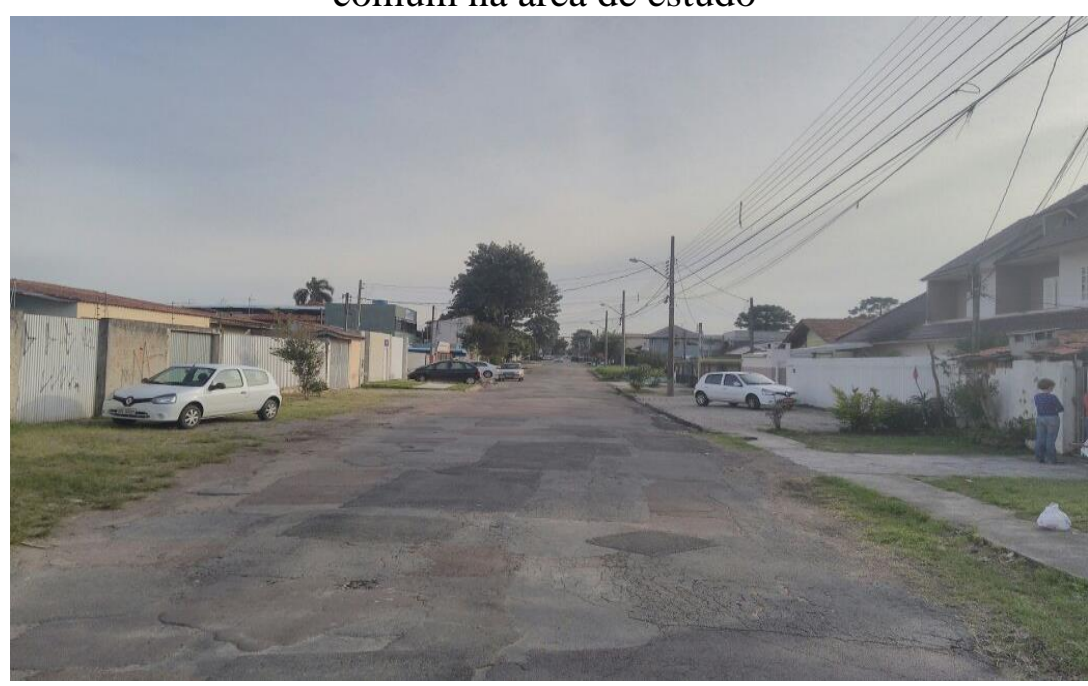

Fonte: Acervo dos autores, 2017.

Quanto ao atendimento por linhas de ônibus, segundo constatado em área e com auxílio do site da URBS (Companhia de Urbanização de Curitiba), a área é atendida por três linhas de ônibus: duas que passam na Rua Dr. Júlio César Ribeiro de Souza (021 Interbairros 2 e 338 - Centenário-Hauer) e uma linha que passa na rua Canal Belém (475 Canal Belém).

Pode-se constatar que os moradores necessitam andar menos de $500 \mathrm{~m}$ para acesso a transporte público, sendo um índice considerado aceitável. A menos de $1000 \mathrm{~m}$ do setor escolhido, encontra-se um dos maiores terminais de ônibus da região (Terminal Hauer), bem como avenidas rápidas que dão acesso ao centro da cidade e para os bairros vizinhos (Boqueirão, Xaxim, Guabirotuba e Jardim das Américas). Assim, os moradores andam poucas quadras para ter acesso a transporte público que, com baldeações (ou não), os leva a vários pontos da cidade.

A rua principal que atravessa o rio (Rua Dr. Júlio César Ribeiro de Souza), a partir do bairro Uberaba para o Vila Hauer, e é o limite sul da área de estudo possui grande movimento com muitos ônibus de linha e carros de passageiros, causando inclusive lentidão no trânsito, além de altos níveis de poluição sonora. Em análise de campo, pode-se dizer que esse fluxo 
intenso possivelmente cause uma sobrecarga de peso na ponte, pois se notou um perigo de desabamento e erosão na estrutura da ponte (Figura 11).

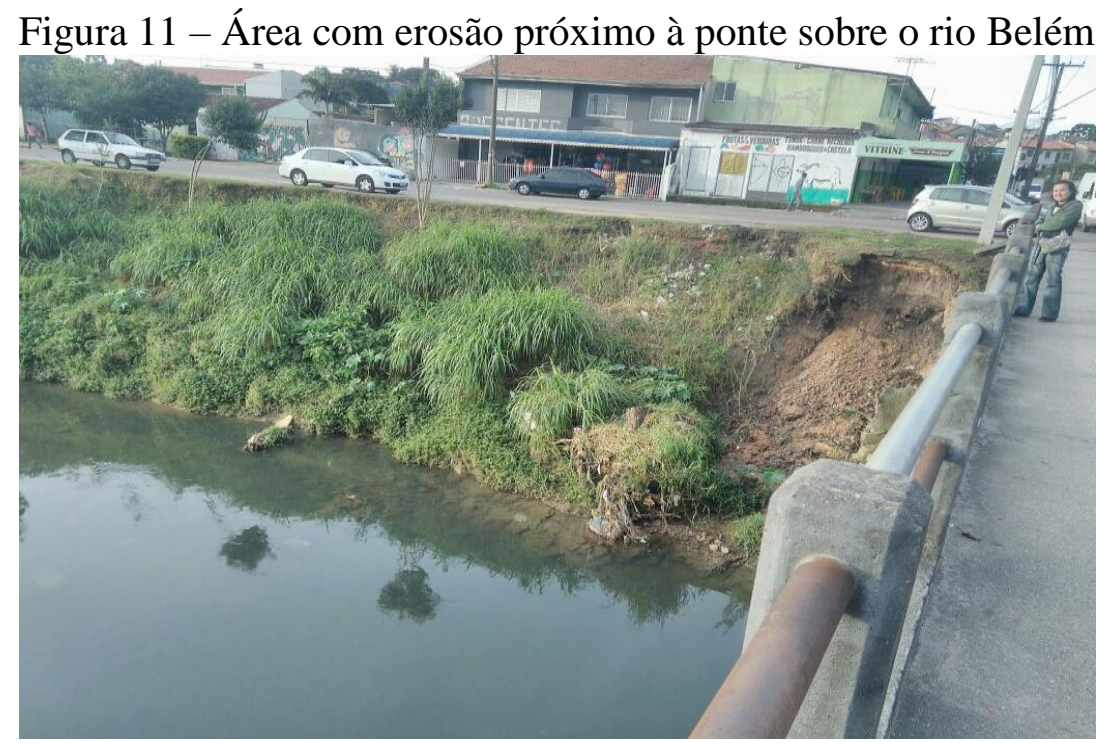

Fonte: Acervo dos autores, 2017.

Mesmo com o atendimento por linhas de ônibus na região, a área de estudo carece de melhorias quanto aos acessos aos pedestres. Além disso, constatou-se que os passeios, em sua grande maioria, não possuem continuidade, dificultando os trajetos e impossibilitando o uso por pessoas com mobilidade reduzida e o fluxo de bicicletas. Algumas vias, caminhos, pontes e calçadas estão em condições precárias, estando, em muitos casos, fora dos padrões urbanísticos da cidade, podendo ser constatado claramente este aspecto, ao se verificar e se comparar com outras regiões do bairro ou de bairros vizinhos.

\section{CONSIDERAÇÕES FINAIS}

A sustentabilidade urbana é um fator fundamental para o planejamento urbano e ambiental adequado das cidades. Embora muito se tenha pesquisado e apresentado sobre o tema, ainda pouco se tem visto realizar na gestão das cidades. Muitas vezes, por questões políticas ou interesses exclusivamente capitalistas, o meio ambiente no meio urbano é deixado de lado e, consequentemente, problemas que influenciam a qualidade ambiental local tendem a aumentar.

O estudo permitiu concluir que o planejamento urbano não é igualitário, até mesmo dentro de um mesmo bairro, e que muito ainda se necessita realizar, para se atingir bons indicadores e índices de sustentabilidade urbana. A área também se encontra um pouco impactada com arborização viária inadequada, porém apresentando bom índice de cobertura vegetal. 
Os usos mistos do solo apresentam pouca heterogeneidade, não servindo à população com os serviços ali instalados, mas sim a outros prestadores de serviços. Os espaços para pedestres se apresentam em condições inadequadas para pedestres e, em muitos trechos, estão fora do padrão urbanístico da prefeitura. Cabe ressaltar também que, apesar de um bom índice de cobertura vegetal, os espaços públicos oferecidos à população são de baixa qualidade ou mesmo, em alguns casos, inexistentes.

Dentre as possibilidades de intervenções urbanísticas na área e, consequentemente, no bairro, incluem-se procedimentos simples, tais como: o cultivo e manutenção de uma arborização viária adequada, a fiscalização quanto aos recuos de calçadas, respeitando o padrão da prefeitura, além de incentivos aos moradores em melhorias (conservação) e aumento da cobertura vegetal. A própria revitalização do rio Belém, controlando os despejos inadequados de resíduos sólidos e esgotos, viria também a ser um fator determinante na melhoria da qualidade ambiental do seu entorno.

Assim, a leitura final do trabalho possibilitou compreender a necessidades de análise de indicadores ambientais, pois esses estão diretamente relacionados ao bom funcionamento da cidade e com a qualidade de vida de seus habitantes.

\section{REFERÊNCIAS}

ACSELRAD, Henri. A duração das cidades: sustentabilidade e risco nas políticas urbanas. 2. ed. Rio de Janeiro: DP \& A, 2001.

BOLLMANN, Harry Alberto; EDWIGES, Thiago. Avaliação da qualidade das águas do Rio Belém, Curitiba - PR, com o emprego de indicadores quantitativos e perceptivos.

Engenharia Sanitária Ambiental, Curitiba, v. 13, n. 4, p. 443-452, dez. 2008.

CAMPOS, Vânia Barcellos Gouvêa; RAMOS, Rui António Rodrigues. Proposta de indicadores de mobilidade urbana sustentável relacionando transporte e uso do solo. In:

Congresso Luso-brasileiro para o Planejamento Urbano, Regional, Integrado e Sustentável, 1., 2005, São Paulo. PLURIS 2005. São Paulo: Edusp, 2005. p. 1-22. Disponível em: $<$ http://repositorium.sdum.uminho.pt/bitstream/1822/4871/1/Ramos_CI_2_2005.pdf >. Acesso em: 29 jun. 2017.

CAMPOS FILHO, C. M. Cidades brasileiras: seu controle ou o caos. São Paulo, Nobel, 1992.

EDWARDS, Brian. O guia básico para a sustentabilidade. 3. ed. Barcelona: Gustavo Gili, 2008.

FENDRICH, Roberto. Diagnóstico dos recursos hídricos da bacia hidrográfica do Rio

Belém. Curitiba: Assembleia Legislativa do Estado do Paraná, 2002.

HARDER, I. C. F.; RIBEIRO, R. de C. S.; TAVARES, A. R. Índice de área verde e cobertura vegetal para as praças do município de Vinhedo-SP. Revista Árvore, v. 30, n. 2, p. 277-282, 2006.

INSTITUTO de Planejamento Urbano de Curitiba (IPPUC). IPPUC História. Disponível em: <http://www.ippuc.org.br/>. Acesso em: 7 jul. 2017. 
JESUS, Silvia C.; BRAGA, Roberto. Análise Espacial das Áreas Verdes Urbanas da Estância de Águas de São Pedro-SP. Revista Caminhos de Geografia, São Paulo v.20, n.3, p.26-38, 2005.

LEITE, C.; AWAD, J.D.C.M. Cidades sustentáveis: desenvolvimento sustentável num planeta urbano. Porto Alegre: Bookman, 2012.

LUCHIARI, Ailton. Identificação da cobertura vegetal em áreas urbanas por meio de produtos de sensoriamento remoto e de um Sistema de Informação Geográfica. Geography Department, University Of Sao Paulo, [s.1.], p. 47-58, 2001.

Disponível em: <http://www.revistas.usp.br/rdg/article/view/47312>. Acesso em: 29 jun. 2017.

MENDONÇA, Francisco de Assis. O clima e o planejamento urbano de cidades de porte médio e pequeno: proposição metodológica para estudo e sua aplicação à cidade de Londrina/PR. 1994, 300 f. Tese (Doutorado em Geografia) - Universidade de São Paulo, São Paulo, 1994.

MISAEL, Gustavo Yuri Mine. Áreas de preservação permanente, usos conflitantes e cobertura vegetal: um estudo comparativo na bacia do rio Belém, Curitiba-PR. In: Congresso Brasileiro de Educação Ambiental Aplicada e Gestão Territorial, 5., 2016, Fortaleza. Anais... Fortaleza: UFC, 2016. p. 1-19. Disponível em: 〈http://www.vcbeaagt.com/>. Acesso em: 30 jun. 2017.

NUCCI, J.C.; CAVALHEIRO, F. Cobertura vegetal em áreas urbanas - conceito e método. Revista GEOUSP, São Paulo: Depto. de Geografia/USP, p. 29-36, 1999.

NUCCI, J.C. Qualidade ambiental e adensamento urbano. São Paulo: Humanitas/FAPESP, 2001.

NUNES, Maria Fernanda de Oliveira et al. Indicadores de sustentabilidade urbana: aplicação em bairros de Caxias do Sul. Arquitetura Revista, São Leopoldo, Unisinos, v. 12, n. 1, p. 87-100, 8 set. 2016. Disponível em:

<http://revistas.unisinos.br/index.php/arquitetura/article/view/arq.2016.121.08>. Acesso em: 29 jun. 2017.

DA SILVA PEREIRA, Marlos; SAUER, Leandro; FAGUNDES, Mayra Batista Bitencourt. Mensurando a sustentabilidade ambiental: uma proposta de índice para o Mato Grosso do Sul. Interações (Campo Grande), v. 17, n. 2, 2016.

Disponível em: <http://www.interacoes.ucdb.br/article/view/1107>. Acesso em: 7 jul. 2017. RUEDA, Salvador. El urbanismo ecológico. Agencia d'ecologia Urbana de Barcelona,Barcelona, editor Diputación de Barcelona, 2006.

SACHS, Ignacy. Caminhos para o desenvolvimento sustentável. Rio de Janeiro: Garamond, 2002.

SPIRN, Anne Whiston. Ecological Urbanism: A Framework for the Design of Resilient Cities (2011). In: PICKETT, S. T. A.; CADENASSO, M. L.; MCGRATH, B. Resilience in Ecology and Urban Design, USA, springer 2013. 